RELATION BETWEEN THE ABSORPTION SPECTRA, ETC.

\title{
LXVIII.-The Relation Between the Absorption Spectra of Acids and their Salts. Part II.
}

\section{By Robert Wright (1851 Exhibition Scholar).}

IN a former communication (T., 1913, 103, 528) the absorption spectra of several acids and their sodium salts were compared, and it was shown that in many cases change in absorptive power takes place on neutralisation, even when alteration of molecular structure is hardly possible. Hantzsch and Scharf (Ber., 1913, 46, 454, 3570) have further compared various acids with their salts and esters in several different solvents, the results-in as far as they are in common-being in agreement with those published in Part $I$. of this paper; whilst Henri (Ber., 1913, 46, 464, 3650), by measurement of extinction-coefficients, has shown that the sodium salt of formic acid is about three times, and that of acetic acid two and a-half times, less absorptive than the corresponding acid.

In the present paper the work has been extended to metals other than sodium, care being taken that the metal used does not of itself show any absorption in the range of spectrum investigated. In all cases the salts were prepared by neutralising a definite quantity of the acid, either with the metal itself, as in the case of magnesium, or more usually by means of the oxide or hydroxide, so that the different salts of a given acid all contain equal quantities of the same sample of acid, and are therefore of equal purity as far as the acidic radicle is concerned. The only exception to this method of preparation was in the case of zinc acetate, when a recrystallised specimen of the salt was used. 
670 WRIGHT: THE RELATION BETWEEN THE ABSORPTION

TABLE I.

N-Formic Acid.

\begin{tabular}{|c|c|c|}
\hline & $\begin{array}{l}10 \mathrm{~cm} . \\
\text { Spectrum trans- } \\
\text { mitted to } \lambda\end{array}$ & $\begin{array}{l}1 \mathrm{~cm} \text {. } \\
\text { Spectrum trans- } \\
\text { mitted to } \lambda\end{array}$ \\
\hline & 2520 & 2400 \\
\hline salt $\ldots \ldots . . .$. & 2420 & 2320 \\
\hline$a,, \ldots \ldots \ldots . . .$. & 2430 & 2330 \\
\hline 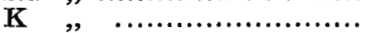 & 2420 & 2320 \\
\hline NH $", \ldots \ldots \ldots \ldots \ldots \ldots \ldots \ldots \ldots$ & 2430 & 2325 \\
\hline 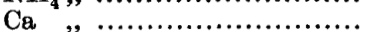 & 2390 & 2320 \\
\hline " & 2400 & 2325 \\
\hline $\mathrm{Ba},, \ldots \ldots \ldots \ldots \ldots \ldots \ldots \ldots \ldots \ldots$ & 2400 & 2320 \\
\hline 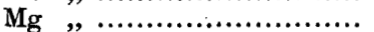 & 2390 & 2320 \\
\hline
\end{tabular}

TABLE II.

N-Acetic Acid.

\begin{tabular}{|c|c|c|c|}
\hline & & $\begin{array}{l}10 \mathrm{~cm} . \\
\text { Spectrum trans- } \\
\text { mitted to } \lambda\end{array}$ & $\begin{array}{l}1 \mathrm{~cm} \text {. } \\
\text { Spectrum trans- } \\
\text { mitted to } \lambda\end{array}$ \\
\hline Acid. & …........................ & 2460 & 2350 \\
\hline salt & [n. & 2400 & 2320 \\
\hline & 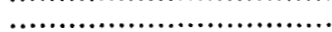 & 2410 & 2320 \\
\hline ,, & 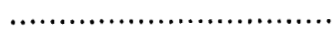 & 2410 & 2320 \\
\hline $\mathrm{NH}_{4}$, & 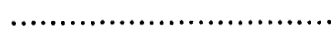 & 2420 & 2320 \\
\hline $\mathrm{Ca} \quad$ & 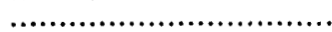 & 2390 & 2325 \\
\hline $\mathrm{Sr}$ & 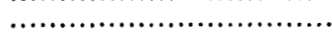 & 2430 & 2330 \\
\hline $\mathbf{B a}$ & 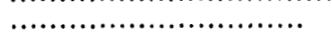 & 2400 & 2325 \\
\hline $\mathrm{Mg}$ & & 2410 & 2325 \\
\hline $\mathrm{Zn}$ & $\ldots \ldots \ldots \ldots \ldots \ldots \ldots \ldots \ldots \ldots \ldots$ & 2400 & 2320 \\
\hline
\end{tabular}

Table III.

N-Propionic Acid.

$10 \mathrm{~cm}$.

$1 \mathrm{~cm}$.

Spectrum trans- Spectrum trans-

Acid................................ $\quad 2480$

Li salt .............................. $\quad 2460$

mitted to $\lambda$

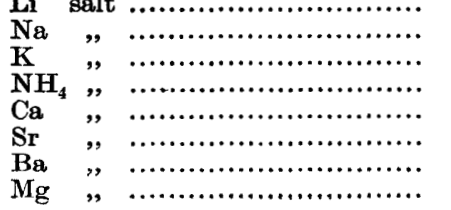

2460

2360

2340

2460

2335

2465

2340

2470

2460

2335

2460

2330

2460

2340

2340

2340 
TABLE IV.

N-Butyric Acid.

\begin{tabular}{|c|c|c|c|}
\hline & & $\begin{array}{l}10 \mathrm{~cm} . \\
\text { Spectrum trans- } \\
\text { mitted to } \lambda\end{array}$ & $\begin{array}{c}1 \mathrm{~cm} . \\
\text { Spectrum trans } \\
\text { mitted to } \lambda\end{array}$ \\
\hline \multicolumn{2}{|c|}{ 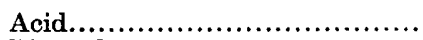 } & 2490 & 2390 \\
\hline $\mathrm{Li}$ sal & 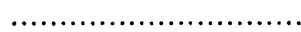 & 2465 & 2330 \\
\hline & .................................. & 2465 & 2330 \\
\hline $\mathbf{K}$ & …........................... & 2460 & 2330 \\
\hline $\mathrm{NH}_{4}$, & 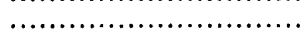 & 2460 & 2330 \\
\hline & ….............................. & 2460 & 2330 \\
\hline $\mathrm{Sr}$ & ….......................... & 2465 & 2330 \\
\hline $\mathrm{Ba}$ & …, & 2470 & 2340 \\
\hline ," & ..................................... & 2460 & 2340 \\
\hline
\end{tabular}

It will be seen that in all cases the neutralisation of the acid, by whatever base, produces the same effect, although in slightly varying degree-that is, the salt is always more diactinic than the acid itself. Thus the quality of the change produced is independent of the metal used, and so must be due to some common property of salts which is non-existent in the corresponding acids. It seems possible that the change in the degree of ionisation which takes place on neutralisation may be the explanation, as in all the above cases the salts are much more highly dissociated than the acids from which they are formed.

In order to determine whether there is any definite relation between the change in absorptive power and the change in the degree of ionisation which takes place on neutralisation, the absorption spectra of a number of inorganic and organic acids of different strengths have been compared with those of their sodium salts. The comparison in all cases was made in aqueous solution, and acids of a complicated nature, which are more or less liable to change of structure on neutralisation, were avoided.

For the sake of convenience, the acids examined are roughly grouped according to their strengths.

Strong Acids.-Most of the strong inorganic acids and their salts are too diactinic to admit of investigation. These diactinic acids include sulphuric, hydrochloric, chloric, perchloric, hydrobromic, and the various phosphoric acids and their salts; again, others such as hydriodic decompose so readily that their examination is impossible. Nitric acid has been shown by Hartley (T., 1902, 81, 556) to have a spectrum identical with that of its potassium salt, and in Part I. of this paper the same has been shown to be true of the moderately strong picric and chloroacetic acids. Benzenesulphonic acid, the absorption-curve of which is shown in comparison with sulphurous acid, has the same absorption as its sodium 
salt, and the same is seen to be the case with bromic and iodic acid, the absorptions of which are here given:

TABLE V.

Bromic acid $(N / 10)$ Spectrum transmitted to

Sodium bromate . 2700

2700

Iodic acid $(N / 10)$

2870

Sodium iodate

2870

$1 \mathrm{~cm}$.

Spectrum trans. mitted to 2490 2490 2710 2710

The conclusion may be drawn that strong acids which do not change their structure on neutralisation show the same absorption as their sodium salts.

Acids of Moderate Strength.-In this group are considered acids of a strength comparable with acetic or formic acid, or, in other words, such acids as obey Ostwald's dilution law and give an ionisation-constant. The fatty acids have already been dealt with, and it is seen that, no matter what metal is used, provided its ion is non-absorbent, the salt is always more diactinic than the acid, the greatest difference between the transparency of acid and salt being found in the case of the strongest acid, falling off as weaker acids are dealt with. The same result was found in the series benzoic, phenylacetic, and phenylpropionic acid, the spectrum of the last being almost identical with that of its salt (Part I). The oxalic acid series was also examined in Part $I$ of this paper, but as the two hydrogen ions of the dibasic acids have different ionisationconstants, it was considered advisable to examine the effect of neutralising each separately.

Oxalic acid $(N / 10)$

Table VI.

HNa salt $(N / 10)$.

$10 \mathrm{~cm}$.

Spectrum trans mitted to

$\mathrm{Na}_{2}$ salt $(N / 10)$ 2900

2900

Malonic acid $(N)$

2740

2520

HNa salt $(N)$

2500

$\mathrm{Na}_{2}$ salt $(N)$

2485

Succinic acid $(N)$

2470

HNa salt $(N)$

2470

$\mathrm{Na}_{2}$ salt $(N)$

2470

$1 \mathrm{~cm}$

Tartaric acid $(N)$

2530

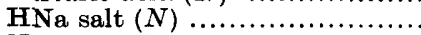

$\mathrm{Na}_{2,}$ salt $(N)$

2510

2470

$\begin{array}{cc}\text { mitted to } & K . \\ 2500 & 10 \cdot 0 \\ 2500 & \end{array}$

$\begin{array}{cc}\text { pectrum trans- } & \\ \text { mitted to } & K . \\ 2500 & 10 \cdot 0 \\ 2500 & \end{array}$

2440

2430

2410

2375

2360

2350

2340

2470

2430

2350

$0 \cdot 163$

$0 \cdot 0066$

0.097 
SPECTRA OF ACIDS AND THEIR SALTS. PART II.

It will be seen that oxalic acid behaves in the same way as a strong acid in the neutralisation of the first hydrogen ion; this, indeed, has been shown by Hantzsch and Scharf in the paper already mentioned, and it is only on replacement of the second ion that an increase in transparency takes place. This result is in agreement with the view that the first ion is much more highly dissociated than the second, and explains why a strong acid like oxalic

Fig. 1.

Frequencics.

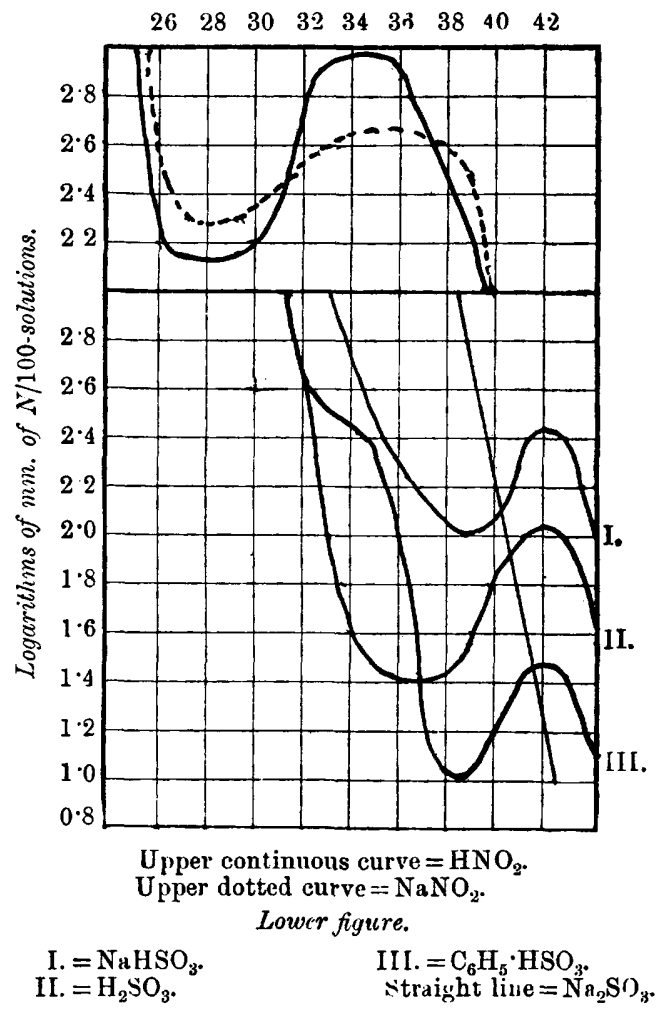

can behave like its weaker homologues, but only with regard to its second or weaker hydrogen ion. In malonic acid both of the carboxyl groups are feebly ionised, so we find a gradual change on the neutralisation of each. The spectra of succinic acid and its salts are practically identical, but on strengthening the acid by the introduction of hydroxyl groups we again find an increase in transparency on neutralisation. 
The absorption curves for nitrous and sulphurous acid and their salts are shown (Fig. 1). In both cases the results are similar to those obtained for moderately strong organic acids, that is, the salts are more diactinic than the acids. It seems probable, however, in the case of sulphurous acid we have a change of structure taking place, for the absorption band, which is well marked in the acid, is absent in the neutral salt. In view of the doubtful constitution of sulphurous acid, the result is of interest, and would probably repay further investigation. The curve for nitrous acid is of somewhat doubtful value, as this substance decomposes very readily; the acid was prepared by adding excess of hydrochloric acid to the requisite quantity of sodium nitrite, the solution being kept at zero by means of ice.

The conclusion may be drawn that in acids of moderate strength the sodium salt is more diactinic than the acid itself, the difference being greatest in the case of the stronger acids, and falling off to nothing with the weaker homologues. It should be noted that this gradation only holds good for the acids of a given series; for example, we cannot compare succinic or phenylpropionic acid with acetic.

Very Feebly Acidic Substances.-This group comprises the phenols and their derivatives, together with such acids as arsenious acid and hydrogen sulphide. Owing to their want of absorptive power, boric acid and hydrocyanic acid cannot be examined. As in the case of the oxalic acid series, the plan has been followed of neutralising the dibasic acids in stages, so that the effect of each replacement of hydrogen can be noted separately.

TABLE VII.

Phenol $(N / 100) \ldots \ldots \ldots \ldots \ldots \ldots \ldots$

Na salt...............................

$p$-Cresol $(N / 100) \ldots \ldots \ldots \ldots \ldots \ldots \ldots$

Na salt.

$o$-Cresol $(N / 100)$

$\mathrm{Na}$ salt.

Thymol $(N / 100)$

Na salt

Guaiacol $(N / 100)$

$\mathrm{Na}$ salt.

o-Hydroxybenzoic acid $(N / 100)$

$\mathrm{CO}_{2} \mathrm{H}$ neutralised ..................

$\mathrm{CO}_{2} \mathrm{H}$ and $\mathrm{OH}$ neutralised
$10 \mathrm{~cm}$. Spectrum trans. Spectrum trans. mitted to

2890

3140

2980

3230

2910

3160

2930

3190

2940

3160 .

3415

3400

3500
K.

$0 \cdot 0_{7} 13$

2840

3060

2930

3180

2850

3090

2870

3090

2880

3090

3310

3260

3390
$0 \cdot 0_{5} 11$

$0 \cdot 0,42$

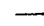

$0 \cdot 102$ 
TABLE VII. (continued).

\begin{tabular}{|c|c|c|c|}
\hline & $\begin{array}{l}10 \mathrm{~cm} . \\
\text { Spectrum trans- } \\
\text { mitted to }\end{array}$ & $\begin{array}{l}1 \mathrm{~cm} . \\
\text { Spectrum trans- } \\
\text { mitted to }\end{array}$ & \\
\hline $\begin{array}{l}p \cdot \text { Hydroxybenzoic acid }(\mathrm{N} / 100) \\
\mathrm{CO}_{2} \mathrm{H} \text { neutralised } \ldots \ldots \ldots \ldots \ldots \ldots \\
\mathrm{CO}_{2} \mathrm{H} \text { and } \mathrm{OH} \text { neutralised } \ldots \ldots \ldots\end{array}$ & $\begin{array}{l}2980 \\
2940 \\
3170\end{array}$ & $\begin{array}{l}2930 \\
2870 \\
3090\end{array}$ & 0029 \\
\hline 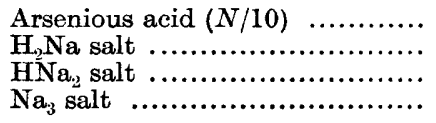 & $\begin{array}{l}2390 \\
2530 \\
2560 \\
2560\end{array}$ & $\begin{array}{l}2250 \\
2380 \\
2410 \\
2410\end{array}$ & - \\
\hline $\begin{array}{l}\text { Hydrogen sulphide }(N / 10) \ldots \ldots \ldots \\
\text { HNa salt } \ldots \ldots \ldots \ldots \ldots \ldots \ldots \ldots \ldots \ldots \\
\text { Nan salt } \ldots \ldots \ldots \ldots \ldots \ldots \ldots \ldots \ldots \ldots\end{array}$ & $\begin{array}{l}2480 \\
2790 \\
2790\end{array}$ & $\begin{array}{l}2330 \\
2680 \\
2680\end{array}$ & 0.0557 \\
\hline
\end{tabular}

The conductivity constants are those given by Kohlrausch, with the exception of the constants for phenol and hydrogen sulphide, which are taken from a paper by Walker (T., 1900, 77, 5). It will be seen that the neutralisation of a very feeble acid causes an increase in the absorptive power. Further, the more strongly acidic carboxylic groups of the hydroxybenzoic acids, more especially in the case of the para-compound, behave like the moderately strong acetic or benzoic acids, in that their neutralisation causes a decrease in absorption, and it is only on neutralisation of the feebly acidic phenolic group that an increase in absorptive power takes place. This effect is much more marked in the para- than in the orthocompound, possibly because the two groups are more separated in the former case, being thus less liable to affect each other. It should also be noted that the neutralisation of the final hydrogen atom in arsenious acid and hydrogen sulphide produces no change in their absorption spectra; this is probably due to the high degree of hydrolysis of these fully neutralised salts, and points to the existence in solution of the acid salts alone. In order to show the effect of gradually increasing the acidic properties of a phenol, the absorption curves are given for $o$ - and $p$-nitrophenols, $2: 4$-dinitrophenol, and picric acid (Fig. 2). It is clear that as the strength of the acid increases, the relation between the absorption of acid and salt undergoes marked change; thus, the large increase in absorption produced on neutralising $o$-nitrophenol $(K=0.000043)$ and $p$-nitrophenol $(K=0.000012)$ has almost vanished in the case of 2:4-dinitrophenol $(K=0.008)$, whilst the strong picric acid shows the same spectrum as its salt. Again, it should be noted that we cannot compare acids of widely different structure, for although 2:4-dinitrophenol is stronger than acetic, yet it behaves in the reverse way on neutralisation, becoming more absorbent instead of more diactinic.

VOL. CV. 
It is very generally held that the change produced on the neutralisation of phenolic substances, especially those containing a nitrogroup, is one of structural rearrangement (Baly, Edwards, and Stewart, T., 1906, 89, 514; also Buttle and Hewitt, T., 1909, 95, $1756)$, and it is quite probable that in some cases this view is correct.

lig. 2.

Frcquencies.

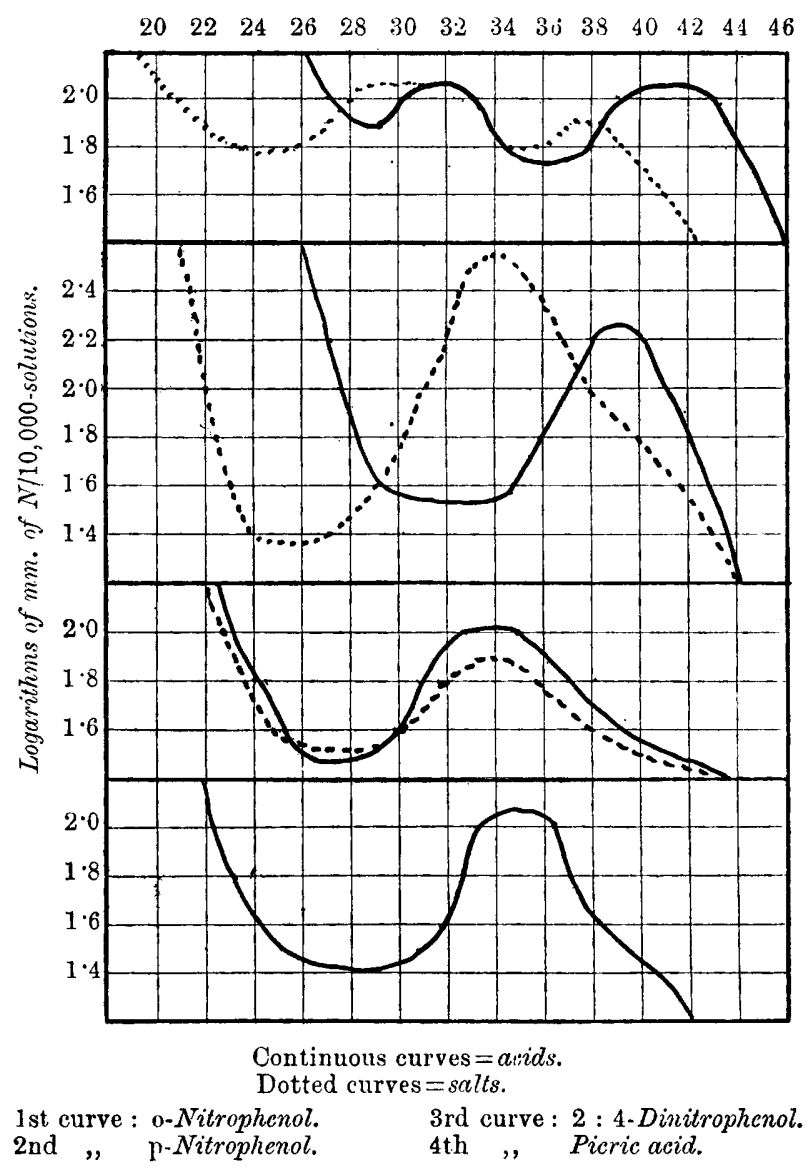

On the other hand, it should be borne in mind that very often no fundamental change is produced in the form of the absorption curve, neutralisation neither creating nor destroying a band, but only altering its position and intensity. It is, indeed, a matter of some difficulty to decide when a change in structure does or 
does not take place; for example, 2:4-dinitrophenol is shown to be similar to, but slightly more diactinic than, its salt. Buttle and Hewitt have, however, shown (loc. cit.) that on adding hydrochloric acid (100 mols. $\mathrm{HCl}: 1$ mol. 2: 4-dinitrophenol), not only is this diactinity greatly increased, but the form of the absorption curve is also changed. In fact, the question would seem to resolve itself into one of degree: How great a change in absorptive power is permissible without assigning change of structure? If the phenoxides differ in structure from their parent substances, is the same true of acetates and formates?

The conclusion may be drawn that very feebly acidic substances are less absorptive than their sodium salts.

Although it is certainly desirable that more extended observations, preferably of a quantitative nature, should be made before any definite conclusions are drawn, still it must be borne in mind that comparisons can only justly be made between acids of a similar nature, and that the absolute certainty of absence of change of structure can never be depended on, more especially in the case of complicated substances. The following explanation has at least the claim of simplicity, and it is in agreement with the so far observed facts.

A simple electrolyte in solution consists of free ions and nonionised molecules; the latter may be considered to be in a state of stress, as they break down on further dilution. The assumption which will be made is that these stressed molecules have an increased power of absorption, being not only more absorbent than free ions, but also than molecules incapable of ionisation, and therefore free from what may be called ionising stress.

Now in strong acids the degree of ionisation approximates more or less with that of the salt, that is, the percentage of stressed molecules is nearly the same in the two cases, and therefore, since neither the acid hydrogen nor the metal which replaces it show any absorption in the range of spectrum investigated, the absorption spectra are identical. With weaker acids, such as formic, acetic, etc., the proportion of non-ionised, and therefore stressed, molecules is much greater than in the corresponding highly ionised salt; we therefore find that the acid is the more absorbent, oxalic acid presenting the interesting case of an acid with one strong and one weak hydrogen atom.

If we now consider the acids of a series, we find that as the acids get weaker their greater absorptive power as compared with their salts diminishes, or even vanishes altogether, whilst extremely feeble acids absorb much less than their sodium salts. This is due to the fact that these very weak acids are almost non-ionisable; that 
is, although there are more non-ionised (stressed) molecules present, yet these molecules are so inert that the ionising solvent has little or no effect on them, and they are therefore stressed to a very small extent. On the other hand, their salts are good electrolytes, and so contain non-ionised molecules capable of ionisation, and therefore in a state of stress, which readily accounts for their greater absorptive power. If we go still further and deal with acids so weak that their salts are practically completely hydrolysed in solution, we arrive at a state where the spectra of acid and salt are again identical. This state seems to have been reached in the case final hydrogen atom in arsenious acid and hydrogen sulphide, for in neither case does the replacement of this atom by sodium produce any change in the absorption spectrum.

We might represent the relation between the absorptive power of a completely ionised salt and its acid, which will be considered capable of existing in any degree of ionisation, by means of the accompanying curve (Fig. 3). The horizontal line represents the unvarying absorptive power of the fully ionised salt, whilst the

Fig. 3.

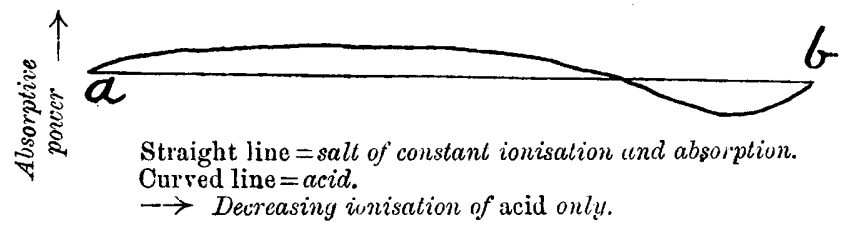

absorption of the hypothetical acid, varying from complete ionisation at $\mathrm{A}$ to absolute inertness at $\mathrm{B}$, is given by the curved line. As the ionisation of the acid decreases, the absorption at first increases, and then diminishes, becoming again equal to, and then less than, that of the salt, the spectra again becoming the same when the acid has grown so weak that its salts are completely hydrolysed.

Summary.-Leaving aside cases of structural change, the results seem to indicate that:

(1) The nature of the change in absorption produced on the neutralisation of an acid by a diactinic base is independent of the base used, but varies slightly in degree with the different bases.

(2) Strong acids show the same absorption as their sodium salts.

(3) Acids of moderate strength, such as acetic, are more absorbent than their sodium salts, the difference between the spectrum of the acid and its salt growing less when we deal with weaker acids.

(4) Very feebly acid substances are less absorbent than their salts. 
ORGANIC DERIVATIVES OF SILICON. PART XXII.

(5) A general explanation of the observed facts can be made by assuming that a non-ionised molecule capable of ionsation exists in a state of stress, and is more absorptive than a similar free ion or than a molecule incapable of ionisation.

UNiversity College, Gower Street.
Quenn's University, Belfast. 